International Journal of Instruction e-ISSN: 1308-1470 • www.e-iji.net
July $2018 \bullet$ Vol.11, No.3

p-ISSN: 1694-609X

pp. 477-490

Received: 02/01/2018

Revision: 24/04/2018

Accepted: 28/04/2018

\title{
Being a Deaf and a Teacher: Exploring the Experiences of Deaf Teachers in Inclusive Classrooms
}

Teketel Agafari Hankebo

Lecturer, Haramaya Univeristy, College of Education and Behavioural Sciences, Department of Special Needs and Inclusive Education, Ethiopia, teketelagafari@yahoo.com

Teaching is a unique and challenging undertaking. Not many can become effective and dedicated teachers. Being a deaf teacher and meeting diverse needs of learners in an inclusive setting also will exacerbate the dilemmas as it calls for multisensory communication and reciprocal interaction with learners. This study focuses on exploring mode of communication and teaching experience and perceptions of deaf teachers in teaching in an inclusive classrooms. Seven deaf-teachers from two primary government schools were selected for the study, using availability sampling technique. Qualitative design was used followed by interpretive phenomenological approach. Semi-structured interview questions and observation checklist were used to collect the data. Sign language interpreters were made use of for the interview. The study revealed that deaf teachers used demonstration, gestures and sign language as modes of communication for the whole class as most of the students lacked sign language skills. The study discovered that though deaf teachers have positive perception for their career, they lacked appropriate pedagogical skills. It also appears that deaf teachers are highly inconvenienced by communication barriers and poor interaction, lack of technology usage, and lack of sign language interpreters. From this study one can surmise that deaf teachers are overlooked within their professional practices.

Keywords: deaf, deaf teachers, inclusive education, teaching, learning

\section{INTRODUCTION}

There is no doubt in anyone's mind that teaching is one of the most demanding and trying professions. Sequeira (2017) defined teaching as a set of events, outside the learners which are designed to support internal processes of learners. According to Sequeira, in modern context the role of teachers in teaching-learning process is facilitating students' learning. In facilitating role teachers required the ability and skills to meet unique needs, identification of individual learners' interest of learning use of multisensory communication and interaction. This also requires teacher's motivation and competence (Nandini and Haseen, 2014).

Citation: Hankebo, T. A. (2018). Being a Deaf and a Teacher: Exploring the Experiences of Deaf Teachers in Inclusive Classrooms. International Journal of Instruction, 11(3), 477-490. https://doi.org/10.12973/iji.2018.11333a 
Teaching in inclusive classrooms is more demanding task for teachers with disabilities in general and the deaf teachers in particular because it requires multi-sensory communication and reciprocal interactions, higher levels of consciousness, coordination, management, guidance, facilitation, collaboration and individualized instruction (Rieser, 2013).

Inclusive education is teaching all students (students with and without disabilities) together in a regular classroom based on the interest of children by making learning meaningful (Makoelle, 2014). It is a process of addressing and responding to the diverse needs of all learners through increasing participation and reducing exclusion within and from education (UNESCO, 1994). Inclusive education involves changes and modifications in content, approaches, structure and strategies to respond to heterogeneous group (Nandini and Haseen, 2014). These change and modification should not be only for the learners with special needs it should work for the teachers with special needs. Teachers' education institutions required modifications and considerations in methods of training teachers with disabilities for inclusive education. Teachers with disabilities should be equipped with necessary skills and knowledge to empower their additional needs in their teaching and learning process because of their disabilities.

Teachers in inclusive classroom should be equipped with the skills to work collaboratively, treat all students as individuals, and reflect on their practices (European Agency for Development in Special, 2010). Teacher education should prepare teachers with knowledge about diverse cultures in schools and society and engage teachers' commitment to work to working in a culturally diverse society (Arthur-kelly, Sutherland, Lyons, \& Foreman, 2013).

When we talk about inclusive education, we are not merely referring to the placement of children with disabilities in a regular school system. In inclusive classrooms, all students, irrespective of their capacities and challenges, will have to actively participate in all activities of regular classrooms and the schools need to be in a position to instill the spirit of collaboration, not exclusion, in all their students (Rieser, 2013). The formation of an inclusive mindset requires persistent efforts, attentiveness and continuous monitoring and evaluating of the existing conditions in order to create a participatory and welcoming school setting (Winter, Raw, \& O’Raw, 2010). Instruction in an inclusive classroom needs to utilize a multisensory communication approach as well as multiple teaching strategies (Reichow, Boyd, Barton, \& Odom, 2016). This article argues that the practice of deaf teachers in an inclusive classroom which requires appropriate usage of technology, proper support, adequate facilities and sign language interpreters who have skills which may affect significantly the effectiveness of deaf teachers.

Having said this, it ought to be reiterated that teaching is a meaningful and challenging task that requires the ability to manage classroom and time, find relevant resources, know all students, adapt learning activities to satisfy the needs of all students, assess the individual growth of each and every student, and give feedback to each student. It also involves performance evaluation and proper communication with students and their 
parents (Henry, 2014) . Teaching activity imparts emotional, social, cultural and moral values to society (Symeonidis, 2015;Pence, 2009).

The trouble with being a deaf and a teacher in an inclusive classroom is that it makes it even harder for the teacher to have the ability to recognize, accept, and respond to the distinctive needs of all children in the setting (Holdheide \& Reschly, 2008).

The fact of the matter is that in Ethiopia, classrooms are very noisy and even hearing teachers find it very difficult to manage their classes. Now imagine the plight of deaf teachers who find it very difficult to hear what children say because of the background noise. This is one the most challenging factors for deaf and hard-of-hearing teachers and learners. Furthermore, teachers should be emotionally stable, active listeners and tolerant. And yet, one of the most recurring characteristics that affect deaf people is their emotional problems and limitation in their communication/interaction. Another challenge that deaf teachers face is their inability to easily understand what learners tell them and explanation on the activities and needs of children- reciprocal interaction.

\section{Statement of the problem}

Effective teaching relies on the quality of teacher's behavior, best communication and positive and clear interactions with their students (Sakarneh, 2004). Teaching in an inclusive classroom may be challenging mission because teachers should have basic characteristics of effective teaching skills and reciprocal interaction (Sakarneh, 2004). Being successful in an inclusive classroom is not easy task. Because a teacher of inclusive class demand ability to deal with learners with different needs and abilities (Sakarneh, 2004). Effective teaching in an inclusive classroom also require use of multisensory teaching skills, a type of instruction and classroom interaction which actively utilizes all of the senses in teaching-learning process which is a natural way to teach learners. Teachers of inclusive classrooms have to be active listener, critical observers and proactive. In addition, Stoffers (2011) pointed out that effective teachers should have good communication skills and use different senses to interact with their students.

Deaf people have their own communication and behavioral characteristics which limits their 'natural' communication and interaction abilities. In addition, the emotional and behavioral disturbances of deaf people may be some of the characteristics that may affect social interactions and daily activities of deaf teachers. This in turn may have an effect on classroom interaction and effective communication between the teachers and students. Lack of effective communication may also takes longer time in classroom instruction, needs additional energy, affect teacher's motivation and student's interest for the lesson.

In this regard, the researcher observed in his longer experience that the deaf teachers practiced challenges in the schools who were teaching in inclusive classrooms without sign language interpreters. Surprisingly, most of the teachers other than seven deaf teachers and highest number of students in the schools were hearing and lacked sign language skills. Almost all of the deaf teachers were teaching physical education except the one who teaches computer skills in addition to physical education. Therefor the aim of this article is to explore the experience of deaf teachers in an inclusive classrooms. 
More specifically, the objectives of this article were to examine modes of classroom communications and interaction with students, parents, teachers and school communities and the major challenges that impede their teaching practices.

In the course of his long experience the researcher interested to answer the following research questions: how are deaf teachers interact and communicate effectively with their students in an inclusive classrooms? What is the experience of deaf teachers in teaching in inclusive classroom? How deaf teachers are perceived teaching in an inclusive classrooms?

Furthermore, though there are plethora of studies in deaf education and educating deaf and hard-of-hearing students, no study has been undertaken related to deaf teachers in Ethiopia since the case is exceptional. Hence, this study was designed and embarked on to bridge the research gap in the area.

\section{METHOD}

This study used qualitative research method and interpretive phenomenological approach so as to explore detail investigation into deaf teachers' effective communication and interaction with their hearing students and the school community and the challenges they face. Interpretative Phenomenological Approach (IPA) produces an account of current experiences in its own terms rather than preexisting theoretical preconceptions (Smith \& Osborn, 2007). IPA explores experiences of individual deaf teacher and personal perceptions of the phenomenon (Smith \& Osborn, 2015). IPA is used to investigate contextual features of deaf teachers' experiences relative to other regular teachers and teaching professional experiences (Smith \& Osborn, 2015). This approach is crucial because in-depth understanding of phenomenology ensures that the most appropriate means is chosen to implement the study and to generate knowledge as to how the deaf teachers training and teaching practices can be improved.

\section{Participants}

Participants of this study were deaf teachers and two principals from the schools. The degree of hearing loss, except for one participant who was hard-of-hearing but could speak and articulate as hearing persons do, the remaining six respondents reported that they were pre-lingual deaf and hearing was difficult for them. As can be evinced from the researcher's observation, six of them could not hear at all and they could not articulate properly because the hearing loss had occurred before two years of age (before the development of oral language). None of them was using hearing aids and they had no cochlear implants.

\section{Educational qualifications of the deaf teachers}

Regarding the training level of the deaf teachers, all of them reported that they had a college diploma; four of the respondents reported that they had diplomas in physical education and the three said that they had diplomas in natural science, social science and language streams. Most of the deaf teachers reported that they are attending their first degree in physical education, computer science, language and special needs education in summer in-service program. However, means of instruction for the teachers in the Universities is still only oral language (lecture) which excludes them from full participation and interaction in classroom instructions. 


\section{Sampling Technique}

The population of the this study was comprised of seven deaf teachers teaching in the two primary schools in Dire Dawa, a town in the Eastern region of Ethiopia. Because of the fewness of the number of deaf teachers in the area, availability sampling technique was used and one principal from each of the said schools were selected for this study purposely because they were expected to have plenty of information about the deaf teachers experience in teaching and the challenges they faced.

\section{Procedures}

College of Education and Behavioral Sciences at the University provided a letter of ethical clearance to conduct the research after thorough evaluation of the topic, objectives and methods of the research. Following the approval of ethical clearance the researcher obtained informed consent from all participants which explained the objective of the research, the benefit of the research result as well as the anonymity of the participants and confidentiality of the data. All the participants- seven deaf teachersshowed their willingness to participate in the research voluntarily. The researcher and the participants in agreement arranged suitable time and place to conduct the interview by using sign language interpreter. Sign language interpreter had a good signing skills as he is degree in sign language and linguistics and long experience in sign language interpretation. During sign language interpretation the deaf culture issues were taken in to consideration.

In addition to interview, data were collected through long period classroom observation when deaf teachers teaching in classrooms and sport field by using a checklist during student-teacher communication, interaction and methods of teaching. The observation checklist questions constitute three parts such as, classroom management, teachers' communicative behaviors and student's interactions behavior. The researcher developed semi-structured interview questions. The interview was transcribed by coding and confirmed with each participant. To make them anonymous, the participants were coded as Dt1, Dt2, Dt3, Dt4, Dt5, Dt6, and Dt7. Dt stands for Deaf teacher and the numbers represents the list of participant deaf teachers against their names from 1 to 7.

\section{Data Collecting Tools}

Data was collected through semi structured interview and observation checklist while deaf teachers were teaching. The interview questions and a checklist for classroom observation were reviewed by three scholars - two assistant professors and one professor- from the department of special needs and inclusive education at the University and modified based on the comments provided by the professors.

The interview questions and observation checklists were prepared by the researcher on issues related to mode of communication and interaction in the classrooms, practices, perceptions and challenges faced during the teaching learning processes, technology usage and support and collaboration with the teachers, school principals and parents. Observation was made four times for 40 minutes in each session with each teacher. The interview was conducted using sign language interpreter with the six deaf teachers and oral language and writing with the one who was hard-of-hearing. The duration of each 
interview session was not less than one hour and conducted in the resource centers of each school. Interview with the school principals was also conducted on the issues related to means of interactions, collaborations, support provision and the challenges and good practices of the deaf teachers for not less than one and half hours with each of them in their offices.

\section{Data analysis and validation}

Data analysis was conducted by an iterative process of reading interview transcripts and observation field note. While reading, the researcher took notes outlining the ideas about how to analyze the data and found possible themes to address. Previously, the researcher wrote open codes identifying major themes and explored these themes in analytic memos. In this process, the condensed meaning units were abstracted and labeled with a code. These themes along with the research questions formed the basis of the coding scheme. In particular, because this study was concerned with experience of deaf teachers, perceptions and challenges the teachers in an inclusive classroom, the researcher examined each data points in relation to these themes.

For validity and reliability, the researcher employ triangulation (convergence across data sources), member check and apparent coherence of the interpretation. The researcher collected data through various sources (participant observation, interview, review of practicum reports on specific issue) and compared data from different sources. Membercheck involve allowing the participant teachers and the school principals to review the data that has been collected. Each participant teacher and the school principals in this study was afforded to read, correct, and make the comments on the transcript of the interviews and the themes found in this study. Also, a set of literature and theoretical frameworks cited herein guided the analysis. The researcher crosschecked codes of all raw data and interpretations to strengthen the analysis and integrate alternative interpretations. Along with comparisons with relevant literature, the researcher also crosschecked the discussion and participant's feedback in interview transcripts to support the reliability of the interpretation.

\section{FINDINGS}

In this part the data obtained via interview and classroom observation from deaf teachers and the school principals is presented. The data obtained were analyzed by categorizing in to three major themes based on the research questions. Such as mode of communication and interaction, deaf teachers teaching and learning experience, and their perceptions in teaching in an inclusive education.

\section{Experiences of deaf teachers}

\section{School experience of the teachers in primary, secondary and colleges}

Regarding the means of instructional communication during their primary, the respondents said that sign language was the main mode of communication throughout primary school years in addition to demonstration and other body languages. Dt2 reported that he started his education from $\mathrm{KG}$ used to sign from grade four. Deaf teachers had better exposure for sign language at early grade levels.

With regard to this, Dt2 responded his words as follows: In KG there was no sign 
language teacher we began to use sign language for classroom instruction in grade four.

All the participants realized that in their secondary and college education there was no sign language interpreters and signing teachers. When they were responded about the support they received in secondary schools and college, they confirmed that the colleges had been provided with textbooks/handouts so that they could study the courses and sometime they were provided with teacher's notes. Most of the participants (Dt1, Dt4, $D T 5, \& D t 7)$ reported that they tried to follow their teacher's lecture by lip-reading and gesture, body language and support from their hearing friends. In this connection, one of the deaf teachers $D t 1$ stated that:

Most of the teachers in secondary and college do not have awareness about deaf students. Even they do not know the presence of deaf students in their class. Some of them suspect that deaf students are not here to learn but to spend time for no purpose. Their expectations of deaf students achievement is negative assuming that deaf students always cheat in exams and that they are not independent learners.

Most of the participants established that the adaptation, modification and other supports provided in the teacher's education was not satisfactory. They reported that the teacher education system is not organized taking into consideration the special needs of deaf trainees. Deaf students were ill-treated in colleges and secondary schools due to lack of appropriate modification and adaptation and lack of well-trained sign language teachers. Likewise, teachers' education institutions were not gave special attention in preparing deaf teachers for inclusive classrooms instruction in pre-service training. The schools and other concerned bodies were not also made their effort to develop the deaf teachers professional skills needed specific to the teachers.

With regard to this Dt4 reported in his statement as follows: continuous professional development program and activities in our school were not relevant to our needs. The programs and short term trainings provided so far were not focused and addressed deaf teacher's pedagogical skills gaps.

Regarding their teaching experience in year, the deaf teachers had a minimum of four and a maximum of ten years. Though the deaf teachers had long experience they lacked adequate knowledge and skills in teaching inclusive classrooms.

As to their Experience in teaching sign language, almost all the respondents reported that they knew and use sign language. However, they did not teach sign language since they are physical education teachers. Only two respondents ( $D t 5$ and $D t 7$ ) reported that sometimes they were required to interpret sign language for deaf students while teachers were needed. One of the participants $(D t 4)$ reported that he is not interested in teaching physical education. Though all of them gave evidence of having adequate skills in signlanguage and had a short term training on special needs and inclusive education, they did not train sign language to their students and the school teachers and lacked pedagogical skills for teaching in an inclusive classrooms. They were not confident about practical knowledge and skills on inclusive classroom teaching methods and specific instructional techniques. In this regard Dt6 affirmed as followed: 
We have no intensive training on specific instructional techniques of teaching inclusive education. We are deficient on how to address both hearing and students with disabilities in the same classes.

Deaf teachers would have to get special consideration during their training at colleges so that they could acquire adequate skills and knowledge on inclusive classroom instruction.

\section{Classroom experiences of the deaf teachers}

All of the deaf teachers were teaching in primary schools (grade 1-8). And an average number of students per class was 65 and average load per week was 20 . With regards to workload of the deaf teachers, there is no workload difference between the hearing teachers and the deaf teachers. The deaf teachers had no compliant on the distribution of workload in the schools. Deaf teachers complained that large class size and big load affect their effective communication and interaction in inclusive classroom.

Concerning inclusivity of their classroom, most of the respondents except Dt2- who had nine students with different types of disabilities, ascertained that they have a minimum of three students with disabilities in their classrooms and hearing impaired children constitute the highest number. In one of the two schools, deaf students embrace the higher number in the inclusive classrooms. All of the deaf teachers realized that they have been teaching both inclusive classes and regular classes (a classroom where there are no children with disabilities). All of the deaf teachers had experience in teaching in an inclusive classrooms constituting children with different types of disabilities (for example, children with hearing impairments, visual impairments, and multiple disabilities). This may tempered deaf teachers' effective inclusive practices which hampered to entertain learners with diverse needs in an inclusive settings. Having children with divers needs (different types of disabilities) may also affect effective communication and interactions without assistant teachers.

As to the use of technologies that are important for making teaching task simple for the deaf teachers, based on the interview results and observation made, the researcher realized that the teachers were not used technology for minimizing the difficulty of teaching task. Concerning the availability and usage of technology, one of the schools principals stated that:

The school has tried its best to train and equip its teachers with computer skills. However, there is no teacher who has a proper computer skill, including the deaf teachers.

The study discovered that deaf teachers were not supported by a variety of technologies. Lack of technology in an inclusive classrooms may exacerbate the difficulty of teaching task for deaf teachers.

The result of the observation disclosed that almost all the participants lacked classroom management skills. Most of the classes were disturbed by the background noise. The researcher, during the observation sessions, realized that students were not paying attention to the lessons properly, the teachers did not provide the students with instruction/direction before the lessons, the lessons were not well organized, and the 
classroom was distracted by some students as well as by another student out of the classroom. For instance, some students were off-tasked, others were busy inside talk and some others were fighting each other.

The researcher noticed that almost all the participants' communication was not multisensory. The teachers lacked the ability to identify individual children's feelings, interest and needs. There was no reciprocal interaction between the teachers and the students. For example, some students with disabilities were not participating in their lessons. Some were not showing interest in the activities in which the teachers was teaching.

From the classroom observations, the researcher confirmed that the instructional activities for the students with disabilities were not adapted. For example, one of the teachers was teaching a child with Cerebral palsy an activity meant for typically developing children. Since most of the deaf teachers had problem with their speech, students were challenged to understand what the teachers were saying. They were incapable of using simple, short and clear explanation except for the (DT4).

Furthermore, the researcher became aware that most of the deaf teachers tended to communicate better with the deaf students than hearing students during the sessions. For example, during one of the observation sessions, the researcher noticed that one of the deaf teachers did not ask any question from the hearing students. However, the researcher noted that five deaf students were asked most of the questions and two deaf students responded to the teacher.

Regarding seating arrangements, deaf students, children with intellectual disabilities, cerebral palsy and low visions were situated in the front row of the class. However, the observer realized that some participants (Dt2 and $D t 7)$ totally removed blind students from the practical physical education classes assuming that they cannot see what deaf teacher demonstrated. When they was responded why they did that (Dt1 and DT4) reported that it is so difficult for deaf teachers to teach bind students using sign language or demonstration as they cannot see what are going on. In this regard Dtl stated as follows in his words:

She cannot see when I demonstrated and it is difficult for here to listen what I am saying because I cannot explain in words properly.

Deaf teachers who cannot produce speech language were challenged in teaching blind children as they cannot explain in oral language and the students cannot see what the deaf teachers demonstrate and signing.

Concerning the evaluation and assessment activities of deaf teachers, the observation results showed that except $(D t 1)$ all the other deaf teachers did not have continuous assessment. Deaf teachers were faced challenge in using a variety of assessment methods in an inclusive classrooms.

All in all, from the observation conducted one can also surmise that most of the participants were not using alternative instructional methods, assessments strategies, technology and they lacked proper support from the schools.

Regarding their experiences in co-curricular activities, most of the participants reported that they were working in different clubs and administrative levels in the same manner 
that hearing teachers did. For example, $D t 3$ is the school pedagogical center coordinator and member of special needs education club. Dtl is working as unit leader of the school and $D t 2, D t 4, D t 5, D t 6$ and $D t 7$ are members of the school sports club and special needs education club. The school directors also confirmed that all of them are participating in different social and co-curricular activities. Deaf teachers may be effective in coordinating and leadership activities such as co-curricular activities, pedagogical centers, and disability centers.

\section{Mode of communication and interactions of deaf teachers in classrooms}

As far as the mode of communication is concerned, except Dt4, all participants reported that they use body language and demonstration methods for instruction purpose and in some cases sign language. They established that communication using body langue, signs and gesture for classroom instructional activities is very difficult. In this regards Dt2 described in his word as follows: Hearing students are not eager to understand when I communicate in body language. The students confused on what I am saying. They changed their faces. This time I also disturbed and put in troubled.

From the interview results and observation, it can be clear understand that the participants were challenged by their inability to communicate easily with their students as most of their students could not easily follow the sign language. None of the deaf teacher used to teach with sign language interpreters or assistant teachers.

Regarding with the effect of lack of interpreters or assistant, they ascertained that fatigue, temper, takes longer time, and feeling of disappointment. In this regard, one of the participants $(D t 1)$ stated as follows:

Oh my God! One of the things that hurt me most is not being able to understand what my students say and students cannot understand what I said to them. Sometimes I feel disappointed of being a deaf teacher.

Another participant (DT5) also confirmed that difficulty of communication between teachers and students saying that:

I am killing most of my time struggling to explain what I want to impart to my students. It is not easy to communicate with someone who cannot speak your language. This is true also in our case.

Regarding the use of interpreters and other support provision, some of the participants (Dt2, Dt3, and Dt5) reported that in some cases when problem goes beyond their capacity to deal with, special needs educators help in interpreting sign language. However, participants $(D t 1, D t 4, D t 6$ and $D t 7)$ confirmed that there is no interpretation support at all. The lack of assistant teachers or sign language interpreter may effect with emotional instability, lack of motivation and confidence and poor interaction between students and the deaf teacher. Learning may occur when there is a reciprocal interaction. It is very tough for deaf teachers to have reciprocal interaction with hearing students in an inclusive classrooms.

\section{Perception of deaf teachers towards teaching in inclusive classrooms}

Concerning the belief of the deaf teachers on their teaching tasks (Dt2, Dt4, Dt5 and 
$D t 7)$ reported that they believed that deaf people could become effective teachers, if they are self-motivated. However, some of the deaf teachers (Dt1, Dt3, and Dt6) they feel disappointed on their tasks. In this regard DT3 stated as follows: I feel disappointed, helpless and discouraged on what the principals and some teachers did.

The result of the report also indicated some of the deaf teachers were miss-placed assuming that they cannot teach other subjects. Dt4 said as follows: I am forced to teach what I did not trained. I am not interested on what I am teaching.

Concerning the miss-placement of deaf teachers one of the school directors confirmed that it is based on students' request that they were assigned in other subject than they were trained. Assigning without interest and different subject than they trained also resulted with lack of motivation in teaching profession among deaf teachers.

Most of them except (Dt1), were not happy in teaching in an inclusive classroom due to lack of support, lack of proper communication, lack of sign language interpreters and assistant teachers. In addition, lack of technology, resources and facility, lack of incentives and in adequate support made deaf teachers demotivated and develop negative feeling towards inclusive education.

Regarding their belief the success in their profession, most of the participants (Dt2, Dt4, $D 3$, Dt6, and $D t 7$ ) confirmed that they are in fear of failure to succeed in their profession because of the negative attitude of community towards them. They reported that school community has no trust in their capabilities. One of the participants (Dt4) stated as follows in this regard:

The school community, including the school directors, has no trust in deaf teachers. They assume that we are not capable of teaching task. Hearing teachers are not enthusiastic to collaborate with us. Even they assume that we are not qualified teachers.

Deaf teachers perceived that the school community including students lacked confidence on deaf teacher's ability to communicate with students.

\section{DISCUSSION}

Result of the this study established that though deaf teacher used sign language at primary school level as the main means of communication/medium instruction, there was no sign language interpreters and appropriate support at secondary schools. A study conducted by Belay, Fantahun, \& Missaye (2016) revealed similar result with the current study finding which confirmed that deaf students are forced to limited social interaction and communication because teachers lacked sign language skills.

The study also discovered that teachers training institutions were not modified and adapted the training curricula to meet the deaf trainee's unique needs. They were not provided with sign language interpreters, specific skills given special consideration for the deaf student-teachers /candidates to prepare them for inclusive classrooms teachers and deaf teachers (Lewis \& Bagree, 2013).Teachers lacked knowledge of inclusion because of lack of appropriate training and rigid curricula (Tefera et al., 2016).

The result of the study asserted that teacher educators in the colleges lacked how they could use sign language. The main means of communication and support provided in teachers education institutions for deaf teacher trainees were handouts, teacher notes and 
peer support (Lewis \& Bagree, 2013). The training for the deaf lacked augmented communication (Maguvhe, 2014).

Surprisingly, this study disclosed that deaf teacher were not using sign language as the main means of communication in the classrooms or trained their students and the school teachers. The schools did not used the deaf teachers as a good opportunity to train sign language for the regular teacher, students and the school community. The schools lacked proper use of human resource and change as a good opportunity to create inclusive school environment.

The result of the study noticed that one of the challenges in inclusive classrooms for the deaf teachers were large class size, big load and diverse types of learners which affect communication and one-to-one interaction (Tefera et al., 2016). It appears that the classrooms constitute different types of children with disabilities with highest number of children without disabilities which demand more energy and takes longer time during instruction. As the classrooms were a mix of children with disabilities, deaf teachers could not interact with all students properly. Hence, both the deaf teachers and the classrooms needs special attention and consideration to bring about real inclusion (Maguvhe, 2014).

This study also established that deaf teachers had severe communication problem with blind children as they cannot see what deaf teachers demonstrate and deaf teachers also cannot explained what they are doing. Because deaf teachers could not use multisensory communication and interaction method in the classrooms (Makoelle, 2014; Al \& Obaid, 2013; Stoffers, 2011).

The result of the study make known that deaf teachers experienced negative emotion (for example, fatigue, distressed, irritated and disappointed) because of poor interaction, lack of proper communication and complexity of the teaching task.

It appears that deaf teachers lacked inclusive classroom management skills (Dunbar, 2004). Lacked content organization and assessment skills (Tefera et al., 2016). Because of lack of good communication and interaction, the classrooms were full of noise, the students could not able to understand what the teacher says, and most of the students in the classrooms were off-tasked. However, deaf teacher could able to interact with deaf students than hearing students and blind learners.

Remarkably, the study revealed that deaf and hearing peers supported each other (Papagrigoraki, 2016) which benefits all hearing and deaf learners in an inclusive classrooms. Deaf teachers should use deaf students as peer tutors to interpreters or assistant them (Tshifura, 2012). Unlikely, deaf and blind students were not support each other.

The result of the study noticed that lack of technologies which make the teaching task easy for deaf teachers exacerbate the difficulty and complexity of teaching task in an inclusive classrooms (Tshifura, 2012; European Agency for Development in Special, 2010).

From the finding of the study one can asserted that though deaf teachers believe that they could be effective in teaching, they perceive that they were distrusted, lacked confidence by school community. Deaf teachers lacked self-motivation, willingness to 
collaborate and commitment to develop their skills in their profession.

\section{CONCLUSION}

Education of deaf students at secondary and college level was affected by inappropriate communication, inadequate support, and negative attitude of the concerned teachers, school principals and the colleges. Teacher education colleges were not provided them with appropriate support and skills for the deaf teachers in pre-service program. They were not supported by relevant continuous professional development programs. The study showed that the major challenges of deaf teachers were lack of pedagogical knowledge and skills specific to deaf teachers and lack of proper support and interpreters in teacher education training institutions. Though, they are exposed in teaching inclusive setting, they were confronted by lack of ability to communicate/interact blind and hearing students.

From the research finding it can be concluded that deaf teachers also challenged by lack of time management skills, classroom management, ability to use various teaching methods and continuous assessment and evaluation skills. There is lack of collaboration among regular teachers which hampered the deaf teacher's effectiveness.

Deaf teachers experienced fatigue, distressed, disappointed, lack of motivation, illemoted. Deaf teachers had limited access to technology. Not many of the deaf teachers use hearing aids and other appropriate technologies to make communication more effective. Because of the specific nature of inclusive classroom due they develop negative attitude towards teaching. Deaf teachers feel that they are not effective in teaching sign language because they assume that teaching sign language to hearing student is difficult. Deaf teachers may be effective in leadership and curricular activities if they get proper support.

\section{Further research direction}

Studies on the teaching experience of deaf teachers in an inclusive setting is new area in Ethiopia. In the future, other in-depth study should be conducted on effectiveness of deaf teachers in inclusive classroom and training of deaf teacher for inclusive classrooms. It is also recommended that a study should be conducted with a larger sample.

\section{REFERENCES}

Al, M., \& Obaid, S. (2013). The Impact Of Using Multi-Sensory Approach For Teaching Students With Learning Disabilities, 9(1), 75-82.

Arthur-kelly, M., Sutherland, D., Lyons, G., \& Foreman, P. (2013). European Journal of Special Needs Reflections on enhancing pre-service teacher education programmes to support inclusion : perspectives from New Zealand and Australia, (April 2014), 37-41. https://doi.org/10.1080/08856257.2013.778113

Dunbar, C. (2004). Best Practices in Classroom Management. Best Practices in Classroom Management, (October), 32.

European Agency for Development in Special. (2010). Teacher Education for Inclusion. European Journal of Special Needs Education (Vol. 12). https://doi.org/10.1080/0885625970120109 
Henry, B. (2014). Teaching profession - policies \& challenges, (May).

Holdheide, L. R., \& Reschly, D. J. (2008). Teacher Preparation to Deliver Inclusive Services to Students With Disabilities.

Lewis, I., \& Bagree, S. (2013). Teachers for All : Inclusive Teaching for Children with Disabilities, 24.

Maguvhe, M. O. (2014). Augmentative and alternative communication: requirements for inclusive educational interventions. International Journal of Educational Sciences, 7(2), 253-260.

Makoelle, T. (2014). Pedagogy of Inclusion: A Quest for Inclusive Teaching and Learning. Mediterranean Journal of Social Sciences, 5(20), 1259-1267. https://doi.org/10.5901/mjss.2014.v5n20p1259

Nandini N and Haseen Taj. (2014). Inclusive Education: Key Role of teachers for its Success.

Papagrigoraki, A. (2016). Peer mediated learning in inclusive education :

Pence, H. E. (2009). Teaching in the 21st Century. Journal of Educational Technology Systems, 38(2), 103-110. https://doi.org/10.2190/ET.38.2.c

Reichow, B., Boyd, B. A., Barton, E. E., \& Odom, S. L. (2016). Handbook of Early Childhood Special Education.

Rieser, R. (2013). Teacher Education for Children with Disabilities Literature Review, (February), 1-163.

Sakarneh, M. (2004). Effective teaching in inclusive classroom: Literature review. Retrieved June, 2(24), 2005. Retrieved from http://www.aare.edu.au/04pap/sak04009.pdf

Sequeira, A. H. (2017). Introduction to concepts of teaching, (September).

Smith, J. A., \& Osborn, M. (2007). Interpretative Phenomenological Analysis, 53-80.

Smith, J. A., \& Osborn, M. (2015). Interpretative phenomenological analysis as a useful methodology for research on the lived experience of pain. British Journal of Pain, 9(1), 41-42. https://doi.org/10.1177/2049463714541642

Stoffers, M. (2011). Using a multi-sensory teaching approach to impact learning and community in 2nd grade classroom.

Symeonidis, V. (2015). The status of teachers and the teaching profession, (March).

Tefera, B., Admas, F., \& Mulatie, M. (2016). Education of Children with Special Needs in Ethiopia : Analysis of the Rhetoric of „, Education For All " and the Reality on the Ground The Ethiopian government has registered a prodigious stride in improving educational access in the last couple of decade, $X X X V(1), 45-97$.

Tshifura. (2012). Managing inclusive education in primary schools of by.

UNESCO. (1994). the Salamanca Statement Framework. Policy, (June), 7-10. https://doi.org/E D -94/WS/ 18

Winter, E., Raw, P. O., \& O'Raw, P. (2010). Literature review of the principles and practices relating to inclusive education for children with special educational needs. 